Article type : Original Manuscript

\title{
Persistent and developing sleep problems: a prospective cohort study on the relationship to poor outcome in patients attending a pain clinic with chronic low back pain
}

Running head - Sleep study

\author{
Authors \\ Amir H Pakpour ${ }^{1}$ PhD (Associate Professor) \\ Mohammadhossein Yaghoubidoust ${ }^{1}$ MD (Research Associate) \\ P Campbell ${ }^{2} \mathrm{PhD}$ (Research Fellow)
}

1. Social Determinants of Health Research Center, Qazvin University of Medical Sciences, ShahidBahounar BLV, Qazvin, 3419759811, Iran, Pakpour_Amir@yahoo.com.

2. Arthritis Research UK Primary Care Centre, Institute for Primary Care and Health Sciences, Keele University, Keele, Staffordshire, United Kingdom.

Please address all correspondence to:

Paul Campbell PhD

Arthritis Research UK Primary Care Centre, Keele University, Keele, ST5 5BG,

United Kingdom. Email - p.campbell@keele.ac.uk, Tel: +44 (0)1782 734828

Fax: +44 (0)1782 733911

This article has been accepted for publication and undergone full peer review but has not been through the copyediting, typesetting, pagination and proofreading process, which may lead to differences between this version and the Version of Record. Please cite this article as doi: 10.1111/papr.12584

This article is protected by copyright. All rights reserved. 


\title{
Funding and conflict of interest statement
}

The authors have no conflicts of interest. No funding sources were provided.

\begin{abstract}
Sleep problems are common in people with low back pain (LBP), however the mechanisms on how sleep influences pain are complex. To date there is a lack of prospective research on the timings and the development of sleep problems in those who have LBP, such information would be useful to identify individuals at risk of poor outcome. Aims are to investigate the predictive role of sleep problems on self-report recovery and pain intensity using logistic regression reporting Odds Ratios (OR). An observational cohort of 761 chronic LBP patients recruited from a pain management clinic participated, and completed data at baseline, and at 6 month follow-up $(n=682)$. Results show an increased odds of reported non-recovery (OR 1.52) and pain intensity (OR 2.69) for those who report sleep problems at baseline. Further analysis on the experience of sleep problems through time show that those with developing sleep problems (i.e. no sleep problems at baseline but reported sleep problems at follow-up) were at increased odds of reporting non-recovery (OR 2.17) and pain intensity (OR 2.95), as was those who reported sleep problems at both baseline and follow-up, for recovery (OR 2.88), and pain intensity (OR 3.45). Those with resolving sleep problems (i.e. sleep problems present at baseline but not at follow-up) were at a decreased odds of non-recovery (OR 0.50) and pain intensity (0.49). Presenting, persistent, and developing sleep problems have a significant impact on recovery for those with LBP, clinicians may wish to consider treatment options that can address sleep problems.
\end{abstract}

\section{Keywords}

Low Back Pain, Sleep, Pain, Recovery, Prospective, Cohort

This article is protected by copyright. All rights reserved. 


\section{Introduction}

Low back pain (LBP) is a common condition affecting most people at some point in their lives. A recent review of 165 studies from 54 countries report a point prevalence rate at $18 \%, 1$ year prevalence rate of $38 \%$, and a lifetime prevalence range of $40 \%$ to $80 \%{ }^{1}$. Recurrence of LBP is also common; a review of cohort studies report an estimated $70 \%$ recurrence rate over 5 years for those with LBP ${ }^{2}$. This has led LBP to have a significant global impact in terms of disability to the individual ${ }^{3,4}$, and a significant financial impact; LBP patients have higher direct and indirect costs compared to other patient groups ${ }^{5}$.

Recently there has been a growth of research attention on the role of sleep, in particular sleep problems, and the effect this may have on the outcomes for those with LBP. Sleep problems associated with back pain are common, a large epidemiological study reported that over half of those who report back pain also reported sleep problems ${ }^{6}$, and a review of 13 LBP studies report a prevalence rate of $58.9 \%$ for people ascribing sleep problems related to their back pain ${ }^{7}$. The influence of pain on sleep, and vice versa, is complex and most likely reciprocal, with evidence of consistent associations between LBP and sleep initiation, sleep disturbance, sleep duration, sleep quality, EEG and polysomnography output, and poor daytime functioning ${ }^{8-10}$. Studies have shown associations between increases in poor sleep quality and increased pain intensity ${ }^{7}$, as well as experimental evidence of a lower pain threshold due to sleep disturbance ${ }^{11}$, and increased risk of psychological morbidity (e.g. depression) due to sleep problems in those who report pain ${ }^{12}$. Current thought on the association between sleep disturbance and pain suggests a key link is the relationship between sleep, fatigue, and psychological morbidity (depression, anxiety), leading to a potential compounding effect on pain perception, function and recovery ${ }^{7,8,10}$. Indeed sleep problems are a diagnostic feature of depression, and therefore it is important to examine potential confounding effects

12. There are also inflammatory processes that associate with the sleep cycle that may modulate nociception ${ }^{8}$. Evidence shows higher sleep disturbance are found within inflammatory populations (e.g. rheumatology and fibromyalgia populations) ${ }^{13,14}$, and recent evidence on chronic LBP participants has shown changes in pro-inflammatory markers (Interluekin-6) linked to sleep disturbance ${ }^{15}$.

This article is protected by copyright. All rights reserved. 
However, to date prospective evidence is limited on the relationship between LBP and sleep problems. Little is known about the timings and sequences on the development of sleep problems in those with back pain, or the impact they have on recovery, something which is reflected within the wider field of pain research ${ }^{9}$. Such information would be useful for clinicians to assist in the identification of individuals who may require additional interventions alongside usual pain management (e.g. sleep hygiene treatment). The primary aim of this current study was to examine the prospective predictive role of sleep problems associated with LBP patient self-report recovery and pain intensity outcomes. Secondary aims were to examine differences over time between LBP patients who have no sleep problems, and those with sleep problems, those who develop sleep problems over time, and those who have a reduction of sleep problems over time. In line with recent prospective evidence for the relationship between sleep and pain ${ }^{9}$, it is hypothesised that, compared to those who do not report sleep problems, those with developing sleep problems will be less likely to report a favourable recovery, and that those with persistent sleep problems will have the worse outcomes overall.

\section{Methods}

This was a prospective study of patients with LBP, and was carried out between February 2014 and December 2014. Full ethical approval was granted by the Medical Ethics Committee at Qazvin University of Medical Sciences.

The cohort was inclusive of a convenience sample of consecutive patients with LBP attending the Outpatient Chronic Pain Clinic, Department of the Neurosurgery, Shahid Rajaee Hospital, Qazvin, Iran. Patients are referred to this chronic pain clinic by their primary care physicians most often when pain persists beyond normal healing time or if pain is recurrent or persistent. Usual care at the chronic pain clinic involves patient education (pain management), prescriptions (NSAIDs), physiotherapy (exercise, spa therapy). Patients are normally assessed for progress at two month intervals, and treatment usually lasts for one year. Patients were eligible to participate in this current study if they had a confirmed diagnosis of CLBP (i.e. persistent LBP with or without referred leg pain for at least 3

This article is protected by copyright. All rights reserved. 
months), were 18 years old or over, and be able to speak and read Persian. Patients were excluded if they had any concurrent medical illness (e.g. cardiopulmonary, central nervous system, diabetes, intellectual disorder, rheumatic diseases), serious spinal pathology (e.g. fracture, metastatic), and/or received spinal surgery. Patients scheduled to attend the outpatient chronic pain clinic were approached over a three month period (February 2014 to April 2014), and invited to take part. As this is a convenience sample of consecutive patients, the recruitment of patients to this study is not aligned to the beginning of treatment for each patient, variation exists on treatment type, treatment stage, pain level, and pain impact of the participating patient population.

Patients were contacted by telephone and screened for eligibility by one of the authors (MY). Eligible patients were invited to take part in the study at the same time as their scheduled appointment. Informed consent was obtained from patients at the time of their appointment, and the patient was asked to complete a questionnaire. Subsequently patients were followed up at 6 months.

\section{Measures}

We used a single item self-report global assessment of change question for the patients perceived level of recovery at 6 month follow-up ${ }^{16,17}$. Such assessments of global recovery have clinical relevance, have been found to have high agreement with clinical assessment, and are suitable for research due to their brevity and simplicity ${ }^{18}$. The question consists of six categories (Completely Recovered, Much Better, Better, No Change, Worse, Much Worse) and participants were asked to indicate one category. A cut off was chosen for this measure on the basis of clinical utility (e.g. identification of subgroup who may benefit from treatment due to no change or worsening outcome over time). This variable was collapsed to form two groups: a recovery group (Completely Recovered, Much Better, and Better) and a non-recovery group (No change, Worse, Much Worse).

Pain intensity was measured using a visual analogue scale (VAS), and patients were asked to rate their pain level at the time of filling out their baseline questionnaire and at 6 month follow up ${ }^{6,19}$. For

This article is protected by copyright. All rights reserved. 
the logistic analysis we based the cut off of 0 or $1(0 \mathrm{~mm}$ to $10 \mathrm{~mm})$ as an indication of patient recovery following previous methodology carried out to identify patient perceived recovery from pain ${ }^{20,21}$. Information was also collected on the duration of LBP from patients at baseline. Patients were asked to signify "How long is it since you had a whole month without any pain?" We categorised the pain duration question into two groups for the analysis (6 months or less versus 7 months or more) following previous methodology ${ }^{22,23}$.

The Pittsburgh Sleep Quality Index (PSQI) was used as a measure of overall sleep quality at baseline and at 6 month follow up. The PSQI measures quality and sleep patterns using 7 domains: subjective sleep quality, sleep latency, sleep duration, sleep efficiency, sleep disturbance, sleep medication, and daytime dysfunction over the previous month. Scoring uses a 0-3 Likert scale with a global score of " 5 " or greater indicating clinically significant sleep problems; this global score was used as the cut off to identify those with sleep problems in this study ${ }^{24,25}$. The PSQI has been used previously in numerous pain population studies ${ }^{26,27}$, and has validation in Persian ${ }^{28}$.

Depressive and anxiety symptoms were assessed using the Hospital Anxiety and Depression Scale (HADS) at baseline. The HADS includes two scales (depression, anxiety) and each scale comprises of 7 items. All items are rated on a Likert-type scale ranging from 0 to 3 , with higher scores indicating higher symptom levels with scores ranging from 0-21 for each scale ${ }^{29}$. The HADS has been translated into Iranian (Persian) and has been shown to be valid and reliable in this setting ${ }^{30}$.

Patients were asked to provide information regarding demographic characteristics at baseline; age, gender, BMI score, and occupational status (working, sick leave, not in work, retired).

This article is protected by copyright. All rights reserved. 


\section{Analysis}

Descriptive statistics of the percentage proportions, mean, median and inter quartile range were presented for all the measures. Initially a prospective model was tested using logistic regression producing Odds Ratios (OR) with 95\% confidence intervals $(95 \% \mathrm{Cl})$. Those with sleep problems at baseline were tested against the reference category of those with no sleep problems at baseline, on both self-reported recovery status, and pain intensity outcome, at 6 month follow-up. A two stage process was applied to each logistic regression model. Firstly an unadjusted model was created to assess the direct relationship between sleep problems and outcome (self-report recovery, pain intensity), and then a multivariable model was created including adjustment for baseline depressive symptoms, baseline pain intensity (within the patient self-report recovery model only), baseline duration of pain, baseline anxiety symptoms, age, gender, BMI, and occupational status. The use of an adjusted model gives important indication of the association whilst controlling for potential confounding (e.g. effect of depression on the sleep to pain pathway), and the use of both an unadjusted and adjusted model allows for inspection of the difference in change due to adjustment which may indicate potential mediation or suppression effects. Further exploratory analysis using logistic regression models was carried out to assess the full range of experience of sleep problems at both baseline and follow-up (prospective and cross sectional associations). Four categories of participants were created based on their sleep problem status at both time points (i.e. baseline and follow-up). The first category (no sleep problems), were participants who reported no sleep problems at baseline and at follow up (used as the reference category within the logistic regression). The second category (developing sleep problems) were those participants who reported no sleep problems at baseline, but did report sleep problems at follow up. The third category (persistent sleep problems) comprised of those participants who reported sleep problems at baseline and at follow up. The final category (resolving sleep problems) were those who reported sleep problems at baseline but did not report sleep problems at follow up. Data analysis was conducted using IBM SPSS version 20.0 .

This article is protected by copyright. All rights reserved. 


\section{Results}

In total 807 participants were approached to take part and 761 agreed at baseline representing a $94 \%$ baseline response rate. At 6 month follow-up 682 participants responded representing an $89 \%$ response rate. Independent t-tests or chi-square were performed to statistically assess the difference in the patent's age, gender, BMI, depression, anxiety and pain intensity, occupation as well as sleep quality between those who responded at 6 months and those who did not respond at 6 month followup, and no differences were found.

Baseline characteristics show a mean age of 41 years with just over $55 \%$ of the cohort being male. Just over $37 \%(n=283)$ reported their last pain free month within the previous 6 months. At baseline $48 \%$ of the cohort indicated they had experienced sleep problems in the previous month and this rose to $67.6 \%$ at 6 months follow-up, with only $4.5 \%$ of participants reporting resolving sleep problems at follow-up. Self-reported recovery at follow-up showed that $58.2 \%$ of the cohort indicated they felt completely recovered, much better or better compared to how they felt at baseline. For pain intensity $38.3 \% \%$ of the cohort reported VAS pain intensity levels at $10 \mathrm{~mm}$ or below at 6 month follow up. Table 1 outlines the characteristics of the cohort.

\section{Patient self-report non recovery}

Table 2 outlines the logistic regression analysis. Results show that the presence of sleep problems at baseline significantly increased the odds of poor recovery by approximately $50 \%$ at 6 month follow up (unadjusted OR 1.52), and this result did not markedly change after adjustment for confounds (adjusted OR 1.50). Exploratory analysis using the no sleep problem category (i.e. no reported sleep problems at baseline and at follow up) as the reference category within logistic regression analysis (see Table 2), show that those with developing sleep problems (i.e. no sleep problems at baseline, reported sleep problems at follow up) were almost over 3 times more likely to report non-recovery at 6 months (unadjusted OR 2.93, 95\% $\mathrm{Cl} 1.53,5.61$ ), and those with persistent sleep problems (i.e. sleep problems reported both at baseline and follow-up) were over 3 times more likely to report a nonrecovery (unadjusted OR $3.24,95 \% \mathrm{Cl} 1.63,6.43$ ), with those who have resolving sleep problems

This article is protected by copyright. All rights reserved. 
(i.e. sleep problems reported at baseline but none reported at follow-up) having a reduced odds of non-recovery (unadjusted $\mathrm{OR} 0.49,95 \% \mathrm{Cl} 0.31,0.78$ ). Within the fully adjusted model, results show that those with developing sleep problems are just over twice the increase in odds of non-recovery (adjusted OR 2.17 95\% Cl 1.04, 4.52), those with persistent sleep problems were just under 3 times the odds of non-recovery (adjusted OR $2.9595 \% \mathrm{Cl} 1.48,5.88$ ), and those with resolving sleep problems were at a reduced odds of non-recovery (adjusted OR $0.5095 \% \mathrm{Cl} 0.31,0.81$ ) at 6 months.

\section{Patient pain intensity}

Results for pain intensity at follow up as the outcome (cut off set at $<10 \mathrm{~mm}$ on VAS to indicate recovery), show an increase in the odds of non-recovery and higher pain intensity for those with sleep problems at baseline with an approximate 2.5 times elevated risk (adjusted OR 2.48, 95\% $\mathrm{Cl} 1.62$, 3.70). Further exploratory analysis shows, that compared to those with no sleep problems reported at baseline and at follow-up, those with developing sleep problems had an increased risk of nonrecovery for pain intensity by just under 3 times in both unadjusted (OR $2.9995 \% \mathrm{Cl} 1.51,5.92)$ and adjusted analyses (OR $2.8895 \% \mathrm{Cl} 1.32,6.31$ ). The effect for those with persistent sleep problems is

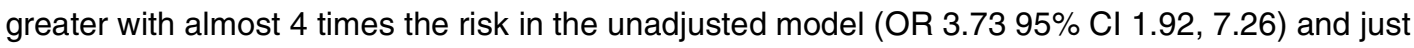
under 3.5 times the risk within the adjusted model (OR $3.4595 \% \mathrm{Cl} 1.59,7.46)$. However those who have resolving sleep problems are more likely to recover compared to those with no sleep problems at baseline or follow up (see Table 3).

\section{Discussion}

This study tested the relationship of sleep problems on perceived recovery and pain intensity on a cohort of LBP patients who attend a pain management clinic. This study tested the prospective relationship as well as examined the effect of persistent, developing and resolving sleep problems on outcomes. Our findings show support to the study hypotheses: the presence of sleep problems is a significant risk factor for non-recovery and pain intensity for those with LBP, also importantly this study reports the elevation of risk of poor outcome in those who develop sleep problems, the added

This article is protected by copyright. All rights reserved. 
strength of risk if the person has persistent sleep problems, as well as a reduction of risk for those whose sleep problems resolve over the course of their back pain.

Comparison to the existing literature shows LBP prevalence is comparable within Iran to European countries, and other countries worldwide, with similar associated risk factors ${ }^{1,31,32}$. Whilst this current cohort reports a higher level of pain intensity compared to community based low back pain or chronic pain samples ${ }^{23,33}$, it does report similar levels to population norms for patients seeking treatments for LBP or attending pain management clinics as is the case in this study ${ }^{34,35}$. The mean score for the PSQI within this current cohort (mean score, 10.5) is generally higher than community dwelling individuals (mean rages 4 to 6$)^{36,37}$, but this study's score is within the expected range for individuals with pain, comorbidity, sleep problems (e.g. insomnia), and poor health ${ }^{38,39}$. In terms of the effect of sleep problems, two recent longitudinal studies report similar significant effects to this study in terms of the role of the reduction in sleep problems in reducing the reports of pain at follow-up and effect sizes reported ${ }^{40,41}$.

A major strength of this study is the prospective design which enabled analysis of the predictive effects of sleep problems on outcomes in people with LBP. In addition the study has been able to describe effects for those who present with sleep problems at baseline, those who subsequently develop sleep problems after baseline, and those where sleep problems have resolved at follow-up which gives a greater perspective on the timings and sequences of sleep problems and the effects they have on patient reported recovery and pain intensity. Another strength of this study is the consideration of potential confounds within the analysis. For example depression has a known reciprocal relationship with both pain and sleep, with sleep problems being a diagnostic feature of depression $^{12,42}$, therefore it was important to account for the potential effects of this within the analysis. Another important factor accounted for within the regression analysis was the duration of back pain prior to the patient entering the study. It was important to control for the effect of duration of back pain because research has shown that those with a longer duration of back pain (i.e. chronic) have an increased risk of poor outcome in general ${ }^{43}$. However this study did not account for other important confounds such as caffeine intake, comorbidity, and medication use (analgesia, sleep

This article is protected by copyright. All rights reserved. 
medication); any one, or all, of these may have influenced the effects reported. There are also limitations in terms of the sample. This study recruited a convenience sample of consecutive patients attending a chronic pain clinic. Firstly, recruitment was not aligned to the treatment stage of each patient (i.e. not every patient was at the beginning of their treatment) and so the trajectory or course of pain and sleep will differ with this case mix. This current study's results on the "developing sleep group" give some insight into these effects, however incidence cohort studies (i.e. onset of sleep problems within those with pain) will be better placed to give greater detail to the patterns and relationships over time. Secondly, severity of symptoms (sleep problems, pain, comorbidity) would be likely to be higher within this current chronic pain clinic cohort, compared to general populations or primary care populations. Therefore the results in this current study may represent an overestimation of the association effects. Nevertheless both primary care and general population samples contain sub populations with high levels of pain and sleep problems ${ }^{7,12}$, where particular individuals may be at similar or higher risk of poor outcome. Whilst the measure of sleep problems used in this study is validated, and broadly used in epidemiological studies ${ }^{24,26}$, it still only captures a subjective rating of sleep quality. The use of objective measures (e.g. polysomnography, actigraphy) may have improved the accuracy of our estimates, although this would have proved difficult to apply in large samples such as this one. Finally whilst there is clinical utility in the use of "cut points" (e.g. in this current study the recovery measure, the pain intensity recovery measure, and the indication of significant sleep problems) to potentially identify groups of patients who may benefit from additional treatment, a limitation is that this study may have missed changes within individuals, within the sub group categories.

The key message derived from the results is that sleep problems significantly predict poor outcome for those with LBP who are seeking treatment. The effect sizes for those presenting with sleep problems at baseline indicate significant increased risk of poor outcome and pain intensity at followup, and examination of groups accounting for the presence of sleep problems through time show larger effects with roughly treble the risk of non-recovery, and presence of pain intensity, due to the presence of sleep problems. Moreover the design of this study allowed an examination of the development of sleep problems, which showed that almost one quarter of patients develop sleep

This article is protected by copyright. All rights reserved. 
problems that associate with poor outcome, whilst in comparison the proportion that resolved was relatively small. This finding highlights not only a need to evaluate and perhaps address sleep problems in the presenting patient, but also to be aware of the potential risk to patients of developing sleep problems, and so monitoring and assessment of sleep problems may be beneficial. A further noticeable finding, albeit in a small proportion, is that those who report that their sleep problems have resolved are more likely to report recovery, compared to those who have not reported sleep problems at all. This may reflect the intrinsic link between pain and sleep ${ }^{10}$, and may suggest that to address both within treatment may have an additive positive effect on recovery, over and above targeting pain or sleep independently. Indeed early evidence is now emerging on the benefits of targeting sleep problems in those with pain; a recent meta-analysis by Tang et al (2015) considered evidence of nonpharmacological Randomised Controlled Trial interventions targeted at sleep for adults who report long term pain ${ }^{44}$. Results show significant reductions in sleep problems, fatigue, and pain at post treatment.

\section{Conclusion}

This study of patients with LBP has shown an increase in risk of poor outcomes in those with LBP who report sleep problems. Clinicians may wish to consider treatment options that involve addressing sleep problems as part of their treatment.

\section{Conflict of interest}

No author has a conflict of interest

This article is protected by copyright. All rights reserved. 


\section{References}

1. Hoy, D., Bain, C., Williams, G., March, L., Brooks, P., Blyth, F., Woolf, A., Vos, T., \& Buchbinder, R. A systematic review of the global prevalence of low back pain. Arthritis \& Rheum, 2012. 64(6), 20282037.

2. Hestbaek, L., Leboeuf-Yde, C., \& Manniche, C. Low back pain: what is the long-term course? A review of studies of general patient populations. Eur Spine J, 2003. 12(2), 149-165.

3. Vos, T., Flaxman, A. D., Naghavi, M., Lozano, R., Michaud, C., Ezzati, M., ... \& Brooker, S. Years lived with disability (YLDs) for 1160 sequelae of 289 diseases and injuries 1990-2010: a systematic analysis for the Global Burden of Disease Study 2010. Lancet, 2013. 380(9859) 2163-2196.

4. Hoy, D., March, L., Brooks, P., Blyth, F., Woolf, A., Bain, C., Williams, G., Smith, E., Vos, T., Barendregt, J., Murray, C., Burstein, R. \& Buchbinder, R. The global burden of low back pain: estimates from the Global Burden of Disease 2010 study. Ann Rheum Dis, 2014. doi:10.1136/annrheumdis-2013-204428

5. Becker, A., Held, H., Redaelli, M., Strauch, K., Chenot, J. F., Leonhardt, C., Keller, S., Baum, E., Pfingsten, M., Hildebrandt, J., Basler, H., Kochen, M., \& Donner-Banzhoff, N. Low back pain in primary care: costs of care and prediction of future health care utilization. Spine, 2010. 35(18), 17141720.

6. Hagen, E. M., Svensen, E., Eriksen, H. R., Ihlebæk, C. M., \& Ursin, H. Comorbid subjective health complaints in low back pain. Spine, 2006. 31(13), 1491-1495.

7. Alsaadi, S. M., McAuley, J. H., Hush, J. M., \& Maher, C. G. Prevalence of sleep disturbance in patients with low back pain. Eur Spine Jl, 2011. 20(5), 737-743.

8. Smith, M. T., \& Haythornthwaite, J. A. How do sleep disturbance and chronic pain inter-relate? Insights from the longitudinal and cognitive-behavioral clinical trials literature. Sleep Med Rev, 2004. 8(2), 119-132.

9. Finan, P. H., Goodin, B. R., \& Smith, M. T. The association of sleep and pain: an update and a path forward. J Pain, 2013. 14(12), 1539-1552.

10. Kelly GA, Blake C, Power CK, O'Keeffe D, Fullen BM. The association between chronic low back pain and sleep: a systematic review. Clin J Pain 2011. Feb;27(2):169-81.

11. Chiu, Y. H., Silman, A. J., Macfarlane, G. J., Ray, D., Gupta, A., Dickens, C., Moriss, R., \& McBeth, J. Poor sleep and depression are independently associated with a reduced pain threshold. Results of a population based study. Pain, 2005. 115(3), 316-321.

12. Campbell P; Tang N; McBeth J; Lewis M; Main CJ; Croft PR; Morphy H; Dunn KM (2013). The role of sleep problems in the development of depression in those with persistent pain: a prospective cohort study. SLEEP, 2013.36(11):1693-1698.

13. Maes M; Libbrecht I; Van Hunsel F; Lin A.H; De Clerck L; Stevens W; Kenis G; de Jongh R; Bosmans E; Neels; $\mathrm{H}$. The immune-inflammatory pathophysiology of fibromyalgia: increased serum soluble gp130, the common signal transducer protein of various neurotrophic cytokines. Psychoneuroendocrinology, 1999.24(4), 371-383.

This article is protected by copyright. All rights reserved. 
14. Mukai E; Nagashima M; Hirano D; Yoshino S. Comparative study of symptoms and neuroendocrine-immune network mediator levels between rheumatoid arthritis patients and healthy subjects. Clin Experi Rheum, 1999.18(5), 585-590.

15. Heffner K.L; France C.R; Trost Z; Ng H.M; Pigeon W.R. Chronic low back pain, sleep disturbance, and interleukin-6. Clin J Pain, 2011. 27(1), 35-41.

16. Mallen, Christian D., George Peat, Elaine Thomas, Simon Wathall, Tracy Whitehurst, Charlotte Clements, Joanne Bailey, Jacqueline Gray, and Peter R. Croft. "The assessment of the prognosis of musculoskeletal conditions in older adults presenting to general practice: a research protocol." BMC Musculoskelet Disord 2006.7, no. 1: 84.

17. Campbell P; Hill JC; Protheroe J; Afolabi E.K; Lewis M; Beardmore R; Hay E.M; Mallen C.D; Bartlam B; Saunders B; van der Windt, D.A; Foster NE; Dunn KM. Keele Aches and Pains Study protocol: validity, acceptability, and feasibility of the Keele STarT MSK tool for subgrouping musculoskeletal patients in primary care. J Pain Res, 2016. 9, 807-817.

18. Kamper S.J; Maher C.G; Mackay G. Global rating of change scales: a review of strengths and weaknesses and considerations for design. J Man Manip Ther, 2013. 17 (3), 163-170.

19. Haefeli, M., \& Elfering, A. Pain assessment. Eur Spine J, 2006.15(1), S17-S24.

20. Kamper, S. J., Maher, C. G., Herbert, R. D., Hancock, M. J., Hush, J. M., \& Smeets, R. J. How little pain and disability do patients with low back pain have to experience to feel that they have recovered? Eur Spine J,2010.19(9), 1495-1501.

21. Hush, J. M., Kamper, S. J., Stanton, T. R., Ostelo, R., \& Refshauge, K. M. Standardized measurement of recovery from nonspecific back pain. Arch Phys Med Rehabil, 2012. 93(5), 849-855.

22. Dunn, K. M., \& Croft, P. R. Classification of low back pain in primary care: using "bothersomeness" to identify the most severe cases. Spine, 2005. 30(16), 1887-1892.

23. Dunn, K. M., Jordan, K., \& Croft, P. R. Characterizing the course of low back pain: a latent class analysis. Am J Epi, 2006.163(8), 754-761.

24. Buysse, D. J., Reynolds, C. F., Monk, T. H., Berman, S. R., \& Kupfer, D. J. The Pittsburgh Sleep Quality Index: a new instrument for psychiatric practice and research. Psychiatry Res,1989. 28(2), 193-213.

25. Backhaus, J., Junghanns, K., Broocks, A., Riemann, D., \&Hohagen, F.Test-retest reliability and validity of the Pittsburgh Sleep Quality Index in primary insomnia. J Psychosom Res, 2002. 53(3), 737-740.

26. Cole, J. C., Dubois, D., \&Kosinski, M. Use of patient-reported sleep measures in clinical trials of pain treatment: a literature review and synthesis of current sleep measures and a conceptual model of sleep disturbance in pain. Clin Therapeutics, 2007. 29(11), 2580-2588.

27. Marty, M., Rozenberg, S., Duplan, B., Thomas, P., Duquesnoy, B., Allaert, F., \& Section Rachis de la SociétéFrançaise de Rhumatologie. Quality of sleep in patients with chronic low back pain: a case-control study. Eur Spine J, 2008. 17(6), 839-844.

28. Moghaddam, J. F., Nakhaee, N., Sheibani, V., Garrusi, B., \&Amirkafi, A.Reliability and validity of the Persian version of the Pittsburgh Sleep Quality Index (PSQI-P). Sleep and Breathing, 2012. 16(1), 79-82.

This article is protected by copyright. All rights reserved. 
29. Zigmond, A. S., \& Snaith, R. P. The Hospital Anxiety and Depression scale. Acta Psychiatr Scand, 1983. 67(6), 361-370.

30. Montazeri, A., Vahdaninia, M., Ebrahimi, M., \& Jarvandi, S. The Hospital Anxiety and Depression Scale (HADS): translation and validation study of the Iranian version. Health and Quality of Life Outcomes, 2003. 1(1), 14.

31. Biglarian, A., Seifi, B., Bakhshi, E., Mohammad, K., Rahgozar, M., Karimlou, M., \& Serahati, S. Low back pain prevalence and associated factors in Iranian populations: findings from the National Health Survey. Pain Res Treat. 2012. 653060.

32. Mousavi, S. J., Akbari, M. E., Mehdian, H., Mobini, B., Montazeri, A., Akbarnia, B., \& Parnianpour, M. Low back pain in Iran: a growing need to adapt and implement evidence-based practice in developing countries. Spine, 2011. 36(10), E638-E646.

33. Breivik, H., Collett, B., Ventafridda, V., Cohen, R., \& Gallacher, D. Survey of chronic pain in Europe: prevalence, impact on daily life, and treatment. Eur J Pain, 2006. 10(4), 287-287.

34. Nicholas, M. K., Asghari, A., \& Blyth, F. M. What do the numbers mean? Normative data in chronic pain measures. Pain, 2008. 134(1), 158-173.

35. Artus, M., van der Windt, D. A., Jordan, K. P., \& Hay, E. M. Low back pain symptoms show a similar pattern of improvement following a wide range of primary care treatments: a systematic review of randomized clinical trials. Rheumatology, 2010. keq245.

36. Buysse DJ, Hall ML, Strollo PJ, Kamarck TW, Owens J, Lee L, Reis SE, Matthews KA. Relationships between the Pittsburgh Sleep Quality Index (PSQI), Epworth Sleepiness Scale (ESS), and clinical/polysomnographic measures in a community sample. J Clin Sleep Med. 2008 Dec 15;4(6):563-71.

37. Hayashino Y, Yamazaki S, Takegami M, Nakayama T, Sokejima S, Fukuhara S. Association between number of comorbid conditions, depression, and sleep quality using the Pittsburgh Sleep Quality Index: results from a population-based survey. Sleep medicine. 2010 Apr 30;11(4):366-71.

38. Smith MT, Perlis ML, Smith MS, Giles DE, Carmody TP. Sleep quality and presleep arousal in chronic pain. Journal of behavioral medicine. 2000 Feb 1;23(1):1-3.

39. Doi Y, Minowa M, Uchiyama M, Okawa M, Kim K, Shibui K, Kamei Y. Psychometric assessment of subjective sleep quality using the Japanese version of the Pittsburgh Sleep Quality Index (PSQI-J) in psychiatric disordered and control subjects. Psychiatry research. 2000 Dec 27;97(2):165-72.

40. Aili, K., Nyman, T., Hillert, L., \& Svartengren, M. Sleep disturbances predict future sickness absence among individuals with lower back or neck-shoulder pain: A 5 -year prospective study. Scan $J$ Pub Health, 2015. 43(3), 315-323.

41. Lusa, S., Miranda, H., Luukkonen, R., \& Punakallio, A. Sleep disturbances predict long-term changes in low back pain among Finnish firefighters: 13-year follow-up study. Int Arch Occup Environ Health, 2014. 88(3), 369-379.

This article is protected by copyright. All rights reserved. 
42. O'Brien, E. M., Waxenberg, L. B., Atchison, J. W., Gremillion, H. A., Staud, R. M., McCrae, C. S., \& Robinson, M. E. Negative mood mediates the effect of poor sleep on pain among chronic pain patients. Clin J Pain, 2010. 26(4), 310-319.

43. Hayden, J. A., Dunn, K. M., Van der Windt, D. A., \& Shaw, W. S. What is the prognosis of back pain? Best Prac Res Clin Rheumatol, 2010. 24(2), 167-179.

44. Tang, N. K., Lereya, S. T., Boulton, H., Miller, M. A., Wolke, D., \& Cappuccio, F. P. Nonpharmacological Treatments of Insomnia for Long-Term Painful Conditions: A Systematic Review and Meta-analysis of Patient-Reported Outcomes in Randomized Controlled Trials. Sleep 2015. Nov 1;38(11):1751-64.

\section{Legends}

\section{Table 1 Cohort characteristics}

Table 2. Logistic regression (LR) with $95 \%$ Confidence Intervals $(95 \% \mathrm{Cl})$ for relationship of sleep problems with non-recovery for those with low back pain.

Table 3.Logistic regression (LR) with $95 \%$ Confidence Intervals (95\% Cl) for relationship of sleep problems with pain intensity for those with low back pain.

This article is protected by copyright. All rights reserved. 
Table 1 Cohort characteristics

\begin{tabular}{|c|c|c|c|}
\hline \multicolumn{4}{|l|}{ Baseline } \\
\hline Characteristic & Number (\%) & mean (SD) & $\begin{array}{c}\text { Interquartile } \\
\text { range }\end{array}$ \\
\hline Age & & $41.15(12.24)$ & 16 \\
\hline Gender (Male) & $414(55.4 \%)$ & & \\
\hline $\begin{array}{l}\text { PSQI Sleep Quality proportion (sleep problems) and scale } \\
\text { score }\end{array}$ & $365(48.0 \%)$ & $10.5(3.5)$ & 5.0 \\
\hline VAS Pain Intensity & & $7.2(2.31)$ & 5.0 \\
\hline Depressive symptoms & & $7.8(4.2)$ & 5.0 \\
\hline Anxiety symptoms & & $11.8(5.2)$ & 8.0 \\
\hline BMI score & & $27.8(6.3)$ & 7.4 \\
\hline Last pain free episode of back pain over 7 months & $478(62.8 \%)$ & & \\
\hline \multicolumn{4}{|l|}{ Occupational status } \\
\hline working & $285(37.5 \%)$ & & \\
\hline sick leave & $151(19.8)$ & & \\
\hline not employed & $220(28.9 \%)$ & & \\
\hline Retired & $105(13.8 \%)$ & & \\
\hline \multicolumn{4}{|c|}{6 month follow-up } \\
\hline $\begin{array}{l}\text { PSQI Sleep Quality proportion (sleep problems) and scale } \\
\text { score }\end{array}$ & $461(67.6 \%)$ & $9.32(3.1)$ & 5.0 \\
\hline \multicolumn{4}{|l|}{ Sleep problem categories } \\
\hline No sleep problems & $190(27.9 \%)$ & & \\
\hline Developing sleep problems & $165(24.2 \%)$ & & \\
\hline Persistent sleep problems & $296(43.4 \%)$ & & \\
\hline Resolved sleep problems & $31(4.5 \%)$ & & \\
\hline \multicolumn{4}{|l|}{ Self-reported recovery } \\
\hline Completely recovered & $143(18.8 \%)$ & & \\
\hline Much better & $91(11.9 \%)$ & & \\
\hline better & $209(27.5 \%)$ & & \\
\hline No change & $58(7.6 \%)$ & & \\
\hline Worse & $114(15.0 \%)$ & & \\
\hline Much worse & $67(8.8 \%)$ & & \\
\hline Missing & $79(10.4 \%)$ & & \\
\hline VAS Pain Intensity & & $5.1(2.4)$ & 5.0 \\
\hline Recovered (VAS $<10 \mathrm{~mm}$ ) & $261(38.3 \%)$ & & \\
\hline Non Recovery (VAS > 10mm) & $421(61.7 \%)$ & & \\
\hline
\end{tabular}

This article is protected by copyright. All rights reserved. 
Table 2. Logistic regression Odds Ratio (OR) with 95\% Confidence Intervals (95\% Cl) for relationship of sleep problems with non-recovery for those with low back pain.

\begin{tabular}{|c|c|c|}
\hline Sleep problem status & $\begin{array}{l}\text { Unadjusted OR } \\
(95 \% \mathrm{CI})\end{array}$ & $\begin{array}{c}\text { Adjusted* OR (95\% } \\
\text { Cl) }\end{array}$ \\
\hline No sleep problems & Reference category & Reference Category \\
\hline Sleep problems & $1.52(1.10,2.08)$ & $1.50(1.09,2.17)$ \\
\hline \multicolumn{3}{|c|}{ Exploratory baseline and follow-up group analysis } \\
\hline No sleep problems (none at baseline, none at follow-up) & Reference category & Reference Category \\
\hline Developing sleep problems (none at baseline, present at follow-up) & $2.93(1.53,5.61)$ & $2.17(1.04,4.52)$ \\
\hline Persistent sleep problems (present at baseline and follow-up) & $3.24(1.63,6.43)$ & $2.95(1.48,5.88)$ \\
\hline Resolving sleep problems (present at baseline, not present at follow-up) & $0.49(0.31,0.78)$ & $0.50(0.31,0.81)$ \\
\hline
\end{tabular}

This article is protected by copyright. All rights reserved. 
Table 3.Logistic regression (LR) with $95 \%$ Confidence Intervals $(95 \% \mathrm{Cl})$ for relationship of sleep problems with pain intensity for those with low back pain.

\begin{tabular}{|c|c|c|}
\hline Sleep problem status & $\begin{array}{l}\text { Unadjusted OR } \\
(95 \% \mathrm{Cl})\end{array}$ & $\begin{array}{c}\text { Adjusted* OR (95\% } \\
\mathrm{Cl})\end{array}$ \\
\hline No sleep problems & Reference category & Reference Category \\
\hline Sleep problems & $2.69(1.72,4.11)$ & $2.48(1.62,3.70)$ \\
\hline \multicolumn{3}{|c|}{ Exploratory baseline and follow-up group analysis } \\
\hline No sleep problems (none at baseline, none at follow-up) & Reference category & Reference Category \\
\hline Developing sleep problems (none at baseline, present at follow-up) & $2.99(1.51,5.92)$ & $2.88(1.32,6.31)$ \\
\hline Persistent sleep problems (present at baseline and at follow-up) & $3.73(1.92,7.26)$ & $3.45(1.59,7.46)$ \\
\hline Resolving sleep problems (present at baseline, not present at follow-up) & $0.46(0.25,0.87)$ & $0.49(0.26,0.93)$ \\
\hline
\end{tabular}

This article is protected by copyright. All rights reserved. 